\title{
The Development of Constructive-Technological Decisions on Creation of a Family of Microelectronic Elements on the «Silicon on Insulator» (SOI) Structures to Provide the Ability to Create Sensors of External Influences of a Various Functional Purpose
}

\author{
M.I. Kakoulin, A.V. Leonov, A.A. Malykh, V.N. Mordkovich, \\ A.B. Odnolko and M.I. Pavlyuk
}

\begin{abstract}
On the example of the magnetic field sensor shown that the developed sensing element type thin-film SOI MISIM transistor with built-in channel provides the creation of sensors with substantially improved electrical characteristics (magnetic sensitivity, temperature range). The physical model of a sensor is considered and justified the choice of the optimal electrical regimes. It is shown that the operation temperature range of the magnetic sensing element is from LHT up to at least $330{ }^{\circ} \mathrm{C}$. Theoretically predicted the possibility of increasing the temperature limit by $200-300{ }^{\circ} \mathrm{C}$ depending on the functional purpose of the sensor. Developed and implemented microelectronic operating voltage stabilizers of sensors and electronic keys operating at temperatures of $230{ }^{\circ} \mathrm{C}$ and not less than $300{ }^{\circ} \mathrm{C}$,
\end{abstract}

M.I. Kakoulin · A.V. Leonov · A.A. Malykh · V.N. Mordkovich (

A.B. Odnolko · M.I. Pavlyuk

JSC, ICC Milandr, Moscow, Russia

e-mail: mord36@mail.ru

M.I. Kakoulin

e-mail: kakoulin@ic-design.ru

A.V. Leonov

e-mail: alex25.08@mail.ru

A.A. Malykh

e-mail: malykhanton21@gmail.com

A.B. Odnolko

e-mail: odnolko@miland.ru

M.I. Pavlyuk

e-mail: mikhail@milandr.ru

(C) The Author(s) 2018

K.V. Anisimov et al. (eds.), Proceedings of the Scientific-Practical Conference

"Research and Development - 2016”, https://doi.org/10.1007/978-3-319-62870-7_4 
respectively. It is shown that the developed sensor and functional elements provide to create multifunctional multi-channel high-temperature sensor of magnetic field and temperature.

Keywords Magnetic sensor $\cdot$ Hall sensor $\cdot$ Temperature sensor

Misim transistor $\cdot$ Accumulation mode $\cdot$ Depletion mode $\cdot$ SOI technology

\section{Motivation}

Lately, the demand for microelectronic sensors that are capable of operating at increased temperatures has substantially elevated in different areas of applications. As an example, automotive, aviation, and space electronics, instrumentation used in the chemical industry, geophysics, oil, and gas industries require sensors that operate in a temperature range of $475-775^{\circ} \mathrm{C}$.

In addition, there is an obvious need in microelectronic sensors that operate in deep cooling conditions down to liquid-helium temperatures (e.g., for control of the characteristics of superconducting magnets in unique physical devices).

It is significant that $\mathrm{Si}$ now is the main semiconductor material for nano- and microelectronic devices including sensors manufacturing. Devices based on bulk single-crystal $\mathrm{Si}$ are not able to satisfy high-temperature microelectronics as far as cryogenic microelectronics. For example, for Si Hall elements, which are the most-used magnetic sensors, the operating temperature limit does not exceed 150 $170{ }^{\circ} \mathrm{C}$ [1]. Such upper limit of operating temperature caused by two factors: (i) leakage of the current of the $\mathrm{p}-\mathrm{n}$ junctions that rapidly increases with the temperature growth and (ii) the thermal generation of exceed electrons and holes in $\mathrm{Si}$, whose concentrations increase with the temperature growth. The conventional method of solving the problem is to apply a wide-band $\mathrm{A}_{3} \mathrm{~B}_{5}$ semiconductors and thin-film multilayer structures for high-temperature sensors based on it, but this solution is much more expensive.

From the other side in case of deep cooling ( $\mathrm{T} \leq 20 \mathrm{~K}$ ), the atoms of donors and acceptors in $\mathrm{Si}$ are in the neutral charge state. In this case, the $\mathrm{p}-\mathrm{n}$ junctions used for separating traditional Hall element from the substrate and the $n^{+}-n$ junctions used for power supply and for measuring the Hall electromotive force (EMF) disappear and the Hall element actually stops operating.

The purpose of this work is to present our results of design and study of silicon sensors manufactured in the base of the «silicon on insulator» (SOI) technology and to demonstrate that SOI thin-film transistors (TFT) as a sensitive elements of magnetic and temperature sensors provide the temperature range extension for $\mathrm{Si}$ sensors as for high temperatures and cryogenic temperature as well. Also discussed the possibility of increasing the operating temperature limit of the microelectronic elements of the service electronics of the sensors. 


\section{Object of Study}

Sensing element represents the double-gate TF MOSFET with built-in $n^{+}-n-n^{+}$ channel and MISIM field-effect control system integrated with traditional Si Hall element in the same structure [2]. Further, it is denoted as field-effect Hall sensorFEHS. It's formed in a thin Si layer of the SOI structure with electron concentration $5 \times 10^{14} \mathrm{~cm}^{-3}$. One of the components of the MISIM field control system is formed by the buried dielectric of the SOI structure $\left(\mathrm{SiO}_{2}\right)$ and by the Si substrate with Al metallization. The other part of the control system is traditional for MOSFETs. The additional $\mathrm{n}^{+}$contacts for Hall-effect measurements are located on the opposite lateral sides of the n-Si operating layer. The fabricated FEHSes were of different geometry and shapes, here are the results for FEHSes with the geometry of $500 \times 500 \times 0.2 \mu \mathrm{m}$ and with both $\mathrm{SiO}_{2}$ oxides of $350 \mathrm{~nm}$ thick.

FEHS can operate in two different modes: in the depletion mode (DM FEHS) near the $\mathrm{Si}-\mathrm{SiO}_{2}$ interfaces (Fig. 1a) and in the accumulation mode (AM FEHS) (Fig. 1b). As one can see from Fig. 1 the main difference of the depletion-mode (DM) FEHS is that there is a peak of the Hall signal in a narrow region of negative gates potentials, that are exceed the module the positive flat-band potential of the

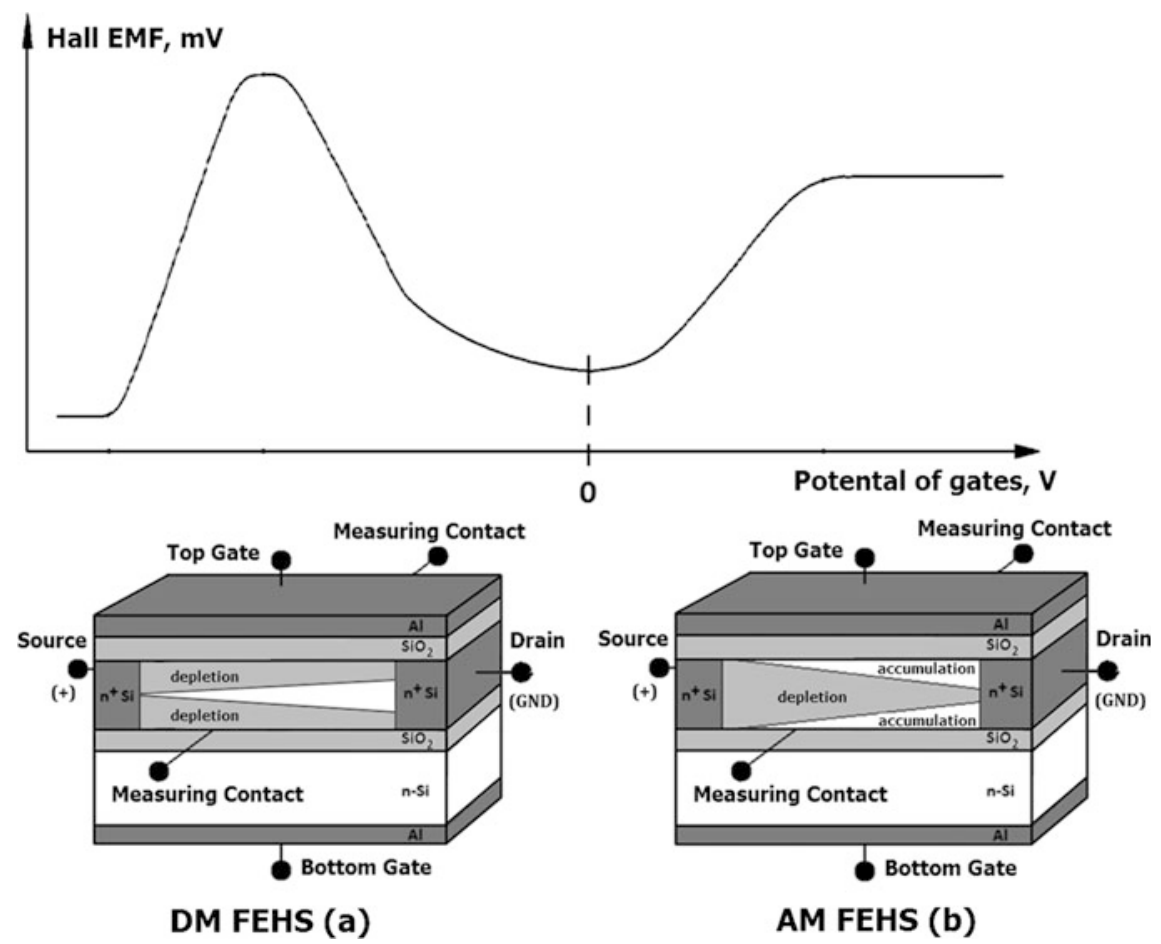

Fig. 1 Typical hall-transfer characteristics of the FEHS and explanation of the design and operation modes: FEHS in depletion mode (a) and FEHS in accumulation mode (b) 
Table 1 The calculated dependence of the maximum value of the Hall EMF from the concentration of electrons in the channel of the DM FEHS at constant values of supply voltage $(4 \mathrm{~V})$ and magnetic induction $(60 \mathrm{mT})$

\begin{tabular}{l|l}
\hline Donor concentration, $\mathrm{cm}^{-3}$ & Hall EMF, $\mathrm{mV}$ \\
\hline $10^{14}$ & 8 \\
\hline $10^{15}$ & 17 \\
\hline $10^{16}$ & 50 \\
\hline $10^{17}$ & 35 \\
\hline
\end{tabular}

accumulation mode FEHS. The amplitude of the peak characterizing the magnetic sensitivity of the DM FEHS is higher than the maximum Hall signal for the AM FEHS, meanwhile the channel current significantly less. In other words, for the magnetic sensitivity DM FEHS is significantly superior to AM FEHS, and increasing the concentration of donors in the channel of the FEHS to values of the order of $10^{16} \mathrm{~cm}^{-3}$, allowing increasing the amplitude of the peak in several times (Table 1). A further increase in donor concentration leads to a decrease in the mobility of the electrons, i.e., to reduce the magnetic sensitivity of the DM FEHS.

The first disadvantage of the FEHS in DM is the narrow dynamic range of the gate potentials in compare to AM FEHS. Also in the context of this work, the increase of the electron concentration in the channel useful, as it extends the range of operating temperatures of the FEHS. But, unlike the DM, AM FEHS allows achieving the increase of operating temperature with almost no change magnetic sensitivity. This, as will shown further, due to the fact that increasing the concentration of electrons in the channel of the AM FEHS is achieved by increasing the potential of the gates, not a change in the concentration of dopant donor impurity in the Si layer of the SOI structure. The said above is the reason for the discussion in the results of the AM FEHS research.

\section{Experimental Results}

The measurements of the AM FEHS were performed in a temperature range of LHT $(1.7 \mathrm{~K})$ up to $335^{\circ} \mathrm{C}$. Figure 2a shows the experimentally measured data of the Hall EMF at the near LHT.

Measurement at this temperature is possible despite the fact that the donor impurity in the channel is not ionized. This is achieved due to the fact that the positive potential applied to the gates of the MISIM field controlling system provides accumulation of electrons supplied from the power source. The maximum operating temperature in our experiments $\left(335^{\circ} \mathrm{C}\right)$ as shown in Fig. $2 \mathrm{~b}$ was not caused by any physical limitations but was determined by the used housings of the AM FEHS. One can see from Fig. 2b, it is also possible to control the magnetically induced signal value by changing the potential of the FEHS gates. 
(a)

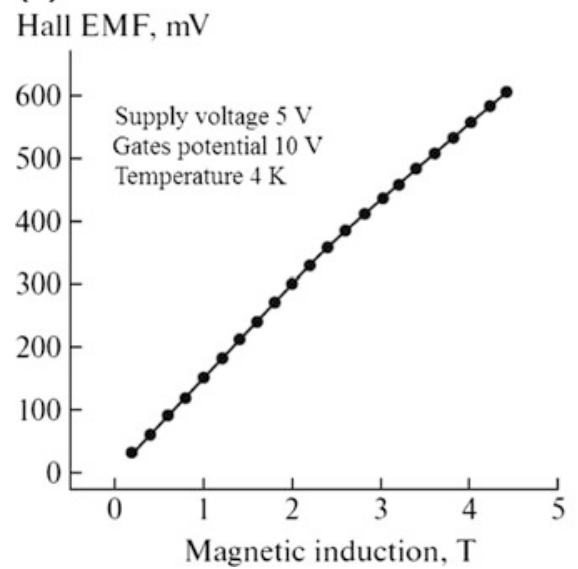

(b)

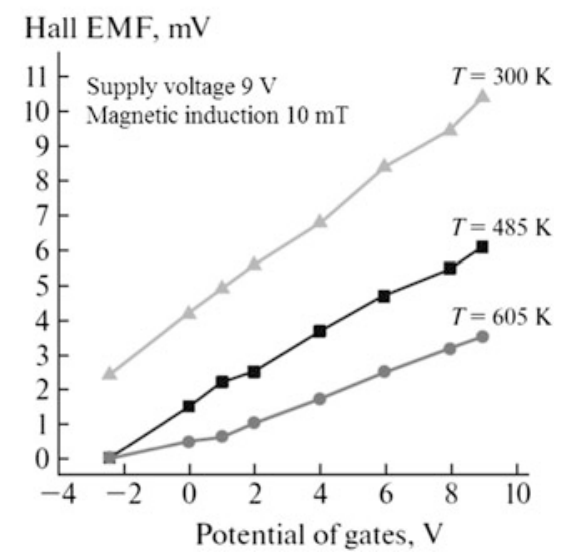

Fig. 2 Experimental results of the AM FEHS measurements: a dynamic range at the near LHT; b Hall EMF over potential of AM FEHS's gates dependencies

\section{Discussion of the Results}

It is known [3] that the use of SOI technology allows to increase the operating temperature of an MOS transistor with an induced channel as compared with analogs made of monocrystalline bulk silicon wafers (MOS transistors with an induced channel are the basis of the CMOS-technology, which is used in the production of the majority of modern silicon and SOI ICs). In a SOI transistor, the areas of the source's and drain's $\mathrm{p}-\mathrm{n}$ junctions are substantially smaller and, hence, the leakage currents are smaller than those of traditional silicon MOS transistors. In this case, for excess current carriers that occur in the substrate with an increase in the temperature, the buried dielectric layer of the SOI structure acts as a barrier that prevents their penetration into the channel of the transistor. It was already shown in early works on SOI MOS transistors that were published in the 1980s-1990s that the operating temperature limit of these transistors is $200-220{ }^{\circ} \mathrm{C}$. This is tens of degrees higher than that of the silicon analogs. With the development of nanotechnology, not only the length of current-conducting channels of SOI MOS transistors, but also their thickness dramatically decreased. In this regard, the area of the $\mathrm{p}-\mathrm{n}$ junctions of the source and drain decreased even more, accordingly, the leakage currents decreased and the operating temperature, which reaches approximately $300{ }^{\circ} \mathrm{C}$ in modern SOI MOS transistors, increased. The field-effect Hall sensor is a SOI transistor with a built-in channel in which $\mathrm{p}-\mathrm{n}$ junctions are absent. Thus, the limitation of the operating temperature by the leakage currents is absent. Notable that the downscaling to nano-sizes is not promising for magnetosensitive transistors of an FEHS. This threatens the sensor with a sensitivity loss since the magneto sensitivity of the Hall elements is higher as longer the distance between the Hall contacts is [4]. It is evident that the increase of the concentration of the 
thermally generated carriers in the area of the partially depleted channel to a value that is close to the average electron concentration in the accumulated area is a substantial limitation on the operating temperature of an FEHS. It follows from here that it is possible to increase the operating temperature of the AM FEHS by increasing the gate potential and accordingly the electron concentration in the accumulated layer. Figure 3 shows the calculated distribution of the concentration of electrons used to estimate the operating temperature limit of the AM FEHS. The calculated estimates of the achievable operating temperature of the AM FEHS by increasing voltages at the gates are summarized in Table 2. These estimates relate to the possibility of using the AM FEHS in magnetic field sensors with an analog output and measurement accuracy of the magnetic field of no worse than $1 \%$. When using such a sensing element in sensors with digital output, in which measurement accuracy is not critical, the operating temperature may be even higher.

According to Fig. 2a, AM FEHS operate comfortably at liquid-helium temperatures when atoms of donors in $\mathrm{Si}$ are completely neutral and electrons are fed to the channel of an FEHS by the power supply. It is known that the MOS transistors can operate in these conditions [5]. However, an AM FEHS possesses certain characteristics that facilitate cryogenic measurements. The gate dielectrics in its MISIM system have a sufficiently high positive built-in charge, which allows the formation of accumulated areas near the interfaces even at small supply voltages and gate potentials. From the physical viewpoint, the measurement of the Hall EMF

Fig. 3 Calculated distribution of the concentration of electrons over the Si film cross-section. The red line shows the level of intrinsic concentration in $\mathrm{Si}$ at the temperature of $575{ }^{\circ} \mathrm{C}$

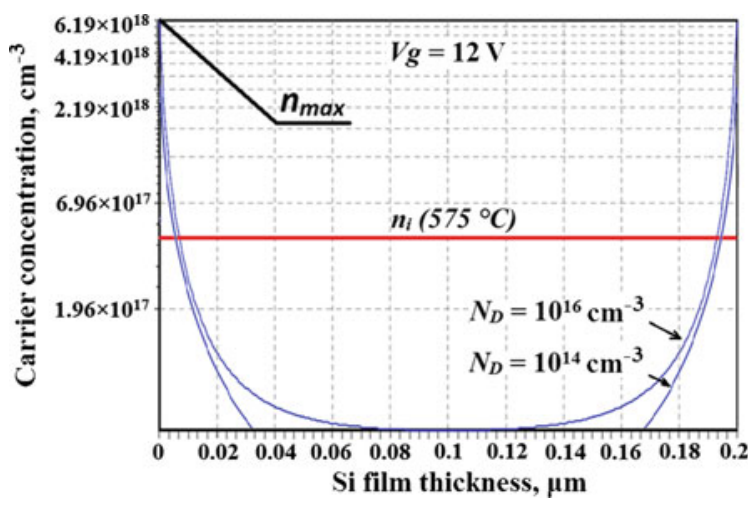

Table 2 The estimated operation temperature limits of the FEHS

\begin{tabular}{l|l|l|l}
\hline $\begin{array}{l}\text { Initial } \\
\begin{array}{l}\text { concentration of } \\
\text { donors } N_{D}, \mathrm{~cm}^{-3}\end{array}\end{array}$ & $\begin{array}{l}\text { Potentials at the } \\
\text { FEHS's gates } V_{g}, \\
\mathrm{~V}\end{array}$ & $\begin{array}{l}\text { Average concentration of } \\
\text { electrons in accumulated } \\
\text { areas, cm }\end{array}$ & $\begin{array}{l}\text { Estimated operating } \\
\text { temperature limit, } \\
\text { C }\end{array}$ \\
\hline $5 \times 10^{14}$ & 4 & $2.7 \times 10^{15}$ & 325 \\
\cline { 2 - 4 } & 8 & $1.2 \times 10^{16}$ & 375 \\
\cline { 2 - 4 } & 12 & $2.9 \times 10^{16}$ & 425 \\
\cline { 2 - 4 } & 38 & $2.9 \times 10^{17}$ & 575 \\
\hline
\end{tabular}


at temperatures below $20 \mathrm{~K}$ (i.e., in conditions of the neutrality of donor impurity atoms) are of special interest. They allow one to study the influence of surface states near the $\mathrm{SiO}_{2}-\mathrm{Si}$ interfaces on the carrier mobility since the contribution of the volumetric carrier mobility in silicon to the Hall signal in this temperature range remains unchanged.

Let us describe the data on the influence of temperature changes in the practically important range $\left(-25\right.$ to $\left.325^{\circ} \mathrm{C}\right)$ on a Hall EMF at constant supply voltages, gate potentials, and magnetic induction in the process of measurements (Fig. 2b). According to the figure, the Hall EMF decreases monotonically with the increase in the temperature, which is mainly related to a decrease in the electron mobility [6]. In magnetic sensitive ICs, it is accepted to compensate for this effect by using an additional electron unit as a part of the sensor to decrease the influence of mobility changes on the measured signal [7]. However, for an FEHS-based sensor, this problem can be solved by changing the potentials of the gates that are included in the feedback circuit with Hall contacts [8]. In this case, the temperature coefficient of the dependence of the magnetic sensitivity of an FEHS can be decreased to $\sim 0.02 \% /{ }^{\circ} \mathrm{C}$ versus $\sim 0.4 \% /{ }^{\circ} \mathrm{C}$, which corresponds to the traditional Hall Si-element [2].

For research of possibility of development of SOI microelectronic functional elements of the sensors, that are operating-capable at the increased temperatures (up to $225{ }^{\circ} \mathrm{C}$ according to the technical requirements for the contract) in compare to analogs made of bulk Si were developed and investigated schemes of the power supply stabilizer and the electronic key.

It is shown that the temperature range of the power supply stabilizer can reach $230{ }^{\circ} \mathrm{C}$, and the temperature range of the electronic key can reach at least $300{ }^{\circ} \mathrm{C}$. The choice of these two components resulted from our development of a universal multifunction sensor the magnetic field and temperature with a frequency output [9]. Stable operation of such a sensor with a frequency output requires stabilization of the operating current and the use of electronic keys, switching modes of measurement of the magnetic field and temperature sensor. This development, in particular, showed that the main element of the conversion impact in the frequency - multivibrator, can be made on the basis of similar field-effect transistors including thin-film SOI MOSFETs presented in this work.

Thus it is obvious that a microelectronic sensor with frequency output can be created on the base of thin-film SOI sensing element and thin-film n-channel MISIM transistors, using the developed high-temperature voltage stabilizer and an electronic key. Working temperature of the sensor may be at least $300{ }^{\circ} \mathrm{C}$.

\section{Conclusions}

In this work, we proposed and investigated SOI sensing element of sensors of various external factors (magnetic field and temperature), the maximum operating temperature of which $400{ }^{\circ} \mathrm{C}$ higher than that for the silicon analogs and significantly exceeds the requirements of the technical specifications. 
It is expected that the results obtained will be primarily used in sensory devices for spacecraft.

Acknowledgments Research is carried out (conducted) with the financial support of the state represented by the Ministry of Education and Science of the Russian Federation. Agreement (contract) no. 14.576.21.0064 06 Nov. 2014. Unique project Identifier: RFMEFI57614X0064.

\section{References}

1. Бараночников М.Л. Микромагнитоэлектроника. Т. 2. Изд 2-е, доп. М.: ДМК Пресс. 888 с. (c.205-209) (2014)

2. Мордкович В.Н., Бараночников М.Л., Леонов А.В., Мокрушин А.Д., Омельяновская Н.М., Пажин Д.М.: Полевой датчик Холла-новый тип преобразователя магнитного поля. Датчики и системы. 7, С. 33-37 (2003)

3. Colinge, J.P.: Silicon-on-insulator technology: materials to VLSI, 373 p. (231-236). Springer, Berlin (2004)

4. Popovic, R.S.: Hall effect devices, 2nd edn, 412 p. (238). CRC Press, Florida (2003)

5. Rotondaro, A.L.P., Magnusson, U.K., Claeys, C., Flandre, D., Terao, A., Colinge, J.P.: Evidence of different conduction mechanisms in accumulation-mode p-channel SOI MOSFET's at room and liquid-helium temperatures. IEEE Trans. Elect. Dev. T. 40(4), 727732 (1993)

6. Leonov, A.V., Mokrushin, A.D., Omeljanovskaja, N.M.: Features of electron mobility in a thin silicon layer in an insulator-silicon-insulator structure. Semiconductors. T. 46(4), C. 478-483 (2012)

7. Бараночников М. Л. Микромагнитоэлектроника Т. 1. М.: ДМК Пресс. 544 с. (164-165) (2001)

8. Leonov, A.V., Pavlyuk, M.I.: A stabilizer of micro-and small currents based on a field Hall-effect sensor with autocompensation of the temperature effect. Instrum. Exp. Tech. T. 59 (6), 808-809 (2016)

9. Mordkovich, V.N., Leonov, A.V., Malykh, A.A., Pavluyk, M. I.: Multifunctional sensor with frequency output based on SOI TFT double-gate sensing element. Proceedings of the 2nd International Conference on Sensors and Electronic Instrumental Advances, p. 114. Barcelona, Spain, 22-23 Sept 2016

Open Access This chapter is licensed under the terms of the Creative Commons Attribution 4.0 International License (http://creativecommons.org/licenses/by/4.0/), which permits use, sharing, adaptation, distribution and reproduction in any medium or format, as long as you give appropriate credit to the original author(s) and the source, provide a link to the Creative Commons license and indicate if changes were made.

The images or other third party material in this chapter are included in the chpater's Creative Commons license, unless indicated otherwise in a credit line to the material. If material is not included in the chapter's Creative Commons license and your intended use is not permitted by statutory regulation or exceeds the permitted use, you will need to obtain permission directly from the copyright holder.

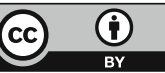

